\title{
El carácter múltiple de la racionalidad estatal: ministerios, funcionarios y desafíos de gobierno en la Argentina
}

\author{
The multiple nature of state rationality. Ministries, officials and government \\ challenges in Argentina
}

\author{
Mariana Gené \\ mariana.gene@yahoo.com.ar \\ Escuela Interdisciplinaria de Altos Estudios Sociales. \\ CONICET/Universidad Nacional de San Martin, \\ Argentina

\section{Mariana Heredia \\ heredia.mar@gmail.com \\ Escuela Interdisciplinaria de Altos Estudios Sociales. CONICET/Universidad Nacional de San Martin, Argentina \\ Luisina Perelmiter \\ lperelmiter@unsam.edu.ar \\ Escuela Interdisciplinaria de Altos Estudios Sociales. CONICET/Universidad Nacional de San Martin, Argentina}

Recepción: 20 Diciembre 2019

Aprobación: 14 Mayo 2020

Publicación: 01 Septiembre 2021

Cita sugerida: Gené, M., Heredia, M. y Perelmiter, L. (2021). El carácter múltiple de la racionalidad estatal: ministerios, funcionarios y desafíos de gobierno en la Argentina. Sociohistórica, 48, e139. https://doi.org/10.24215/18521606e139
Resumen: Los trabajos que describen el sistema político en la Argentina suelen asumir o subrayar la concentración de la toma de decisiones y el carácter presidencialista de la autoridad pública. Sin embargo, la actividad de gobierno conlleva una complejidad y una diversidad de mediaciones que este supuesto no capta. Considerando a los ministerios como una de las principales mediaciones de la decisión gubernamental, y sobre la base de tres estudios de caso en áreas muy distintas del gabinete nacional -Economía, Interior y Desarrollo Social-, este artículo analiza los saberes y destrezas que caracterizan a los funcionarios, los interlocutores relevantes de cada cartera, los atributos institucionales de las mismas y los desafíos de gobierno que enfrentan en diversas situaciones históricas. A partir de ese análisis se identifican tres tipos de racionalidades experta, pragmática y sensible- y se destacan las ventajas de una concepción plural de la racionalidad estatal.

Palabras clave: Ministerios, Funcionarios, Saberes estatales, Gobierno, Racionalidades.

Abstract: The scholarship that describe the political system in Argentina usually assume the concentration of decision-making and the presidential character of public authority. However, government activity implies mediations and a complexity that this assumption does not capture. Considering the ministries as one of the main mediations of state decision-making, and drawing on three case studies in very different areas of the national cabinet - Economy, Interior and Social Development this article analyses officials' knowledge and skills, institutional attributes in each ministry and the government challenges they face in various historical situations. Based on these analyses, we identify three types of state rationalities -expert, pragmatic and sensitive- and show why and how we should embrace a plural conception of state rationality.

Keywords: Ministries, Officials, State knowledge, Government, Rationalities. 
Los trabajos* que describen las características del sistema político en la Argentina suelen centrar su interés en la concentración de la toma de decisiones en la figura presidencial. ${ }^{1}$ Pero, aun cuando la decisión presidencial emanara de la cúspide y eludiera el paso por el Congreso, ¿no es razonable esperar que se vea influida y transformada en su tránsito por los ministerios y sus estructuras burocráticas? ¿En qué medida el "decisionismo" es una categoría sensible a los enredos y múltiples condicionamientos del quehacer de gobierno?

Observar la acción estatal desde sus distintos ministerios constituye una vía de entrada para dar cuenta de las mediaciones - ministros y equipos de gobierno, pero también dispositivos organizacionales o socio-técnicos- que acompañan a los presidentes, habilitando y constriñendo sus decisiones, e incluso traduciéndolas de modos diversos en políticas públicas. Si consideramos entonces a los ministerios como una de las fuentes y mediaciones de la decisión gubernamental, y sobre la base de tres estudios de caso en áreas muy diversas del gabinete nacional -Economía, Interior y Desarrollo Social ${ }^{2}$-, este artículo analiza las racionalidades que predominan en cada área de gobierno. Nos inspiramos para ello en el concepto ampliado de racionalidad de Habermas (1999), para quien la acción racional se define como aquella que pretende una validez susceptible de crítica de acuerdo con: a) su verdad (cognitivo-instrumental), b) su rectitud (prácticomoral) y c) su autenticidad (dramatúrgica-subjetiva).

La idea que articula nuestras reflexiones es que las lógicas de acción que suelen reivindicar estos ministerios son plurales y que solo laboriosa y eventualmente confluyen en una "razón de Estado" conducida y coordinada desde la autoridad central. En otras palabras, los fines estratégicos, la ética, y aun la estética de la acción estatal no responden a un principio universal, sino que se moldean en el entrecruzamiento de varios factores, desde los desafíos de gobierno específicos que afectan a cada área, la historia institucional de esas agencias, hasta el carácter de sus interlocutores claves. Si bien la eficiencia técnico-administrativa suele erigirse en el criterio más frecuente para evaluar la acción estatal, la misma es pasible de ser juzgada de acuerdo con otros criterios como lo son la rectitud legal, la capacidad de reacción ante las demandas sociales, la productividad política, entre otros. Como varios han señalado, desde Max Weber en adelante, es razonable esperar que la tarea de gobierno suponga la coexistencia de lógicas de acción diferentes y que los propósitos de la acción estatal no sean unívocos (Oszlak, 1979; Soprano, 2007). A la reconstrucción de esa pluralidad, y a la identificación de pistas empíricas para elaborar conceptualmente la misma, busca contribuir este texto.

Nuestro interés por los ministerios no avanza en el vacío. Afortunadamente, el estudio del gabinete nacional se robusteció los últimos años. Existen, por un lado, estudios recientes sobre lo que podríamos denominar "los elencos del presidente". Los mismos se fundan tanto en prosopografías que ofrecen una visión desagregada del gabinete de ministros a través del tiempo (Giorgi, 2014), como en investigaciones sobre el personal de ministerios específicos. ${ }^{3}$ En ambos casos, se analizan las trayectorias educativas, sociales y políticas de sus elites, las credenciales que detentan y su desempeño en la historia reciente. Para el período posdictatorial, también se estudiaron la dinámica política de conformación del gabinete y los criterios diferenciales para su nombramiento según presidente y partido político (De Luca, 2011; Camerlo, 2013; Pomares et al., 2014; Ollier y Palumbo, 2016). Asimismo, para el conjunto de los gabinetes ministeriales de América Latina, la ciencia política ha desarrollado varios estudios a partir de metodologías cuantitativas y con el objetivo de establecer diferencias entre regímenes presidencialistas y parlamentarios. ${ }^{4}$ También se avanzó en el estudio de las carteras ministeriales propiamente dichas. Finalmente, Martínez Nogueira (2013) propuso un estudio de la presidencia y de los ministerios en la Argentina como organizaciones estatales de gran heterogeneidad, pero igualmente signadas por profundas debilidades burocráticas.

En este marco general, la reflexión sobre los distintos saberes que nutren la acción estatal ha sido particularmente prolífica. La tensión entre conocimientos "técnicos" y "políticos" o los diferentes "rostros humanos” del Estado ( $c f$. Bohoslavsky y Soprano, 2010), así como la gravitación de expertos de todo tipo 
en la construcción de problemas públicos ( $c f$. Morresi y Vommaro, 2012) son un tema fundamental a la hora de estudiar las distintas carteras de gobierno. Sin duda, fue el ministerio económico, en su estrecha relación con los economistas profesionales, el que más atención recibió a este respecto. ${ }^{5}$ Pero los "saberes de Estado" (Plotkin y Zimmermann, 2012) distan de ser homogéneos y no se reducen a la expertise económica o siquiera a las habilidades respaldadas por un título universitario. Los estudios sobre los distintos ministerios presentan una oportunidad de revisar esos diversos "saberes" que intervienen en la toma de decisiones (ya sea sobre políticas públicas o sobre política en términos amplios), y son probados y reconfigurados al calor de desafíos concretos. Aunque el análisis agregado de las certificaciones universitarias de los funcionarios y equipos de gobierno sea un indicador importante de los recursos intelectuales que orientan su acción (Alcántara, 2012), esta definición de saber es estrecha e impide considerar la diversidad de conocimientos y destrezas que movilizan los funcionarios públicos en los distintos espacios institucionales en los que intervienen.

En la intersección entre las personas y las organizaciones, y en el marco de la multiplicidad de saberes que moviliza el Estado, este texto hace foco en las lógicas de acción que caracterizan a diferentes áreas del quehacer gubernamental. El artículo se organiza de la siguiente manera. En primer lugar, nos detenemos en ciertas características de los elencos, desafíos e interlocutores de los ministerios del gabinete nacional. En segundo lugar, desarrollamos los vínculos entre determinadas lógicas de acción y espacios de gobierno concretos. Ilustramos la pluralidad de racionalidades estatales mediante tres carteras altamente contrastantes -Economía, Interior y Desarrollo Social-, tanto por sus historias institucionales y rasgos organizacionales como por sus tipos de elencos, dispositivos técnicos y pruebas específicas. En la conclusión, reflexionamos brevemente en torno a las implicancias de los contrastes observados para una reconstrucción sistemática de las racionalidades del Estado.

\section{EL GABINETE NACIONAL Y SUS MINISTERIOS: ALGUNAS DIMENSIONES DEL ANÁLISIS}

\section{Saberes y destrezas de gobierno}

Dada la asociación de ciertos ministerios con profesiones específicas, un modo de analizar las lógicas de acción predominantes en cada cartera podría ser el de considerar las especialidades técnico-profesionales que priman en ellas. En efecto, la mayoría de las contribuciones que analizan el vínculo entre conocimiento y gobierno tienden a reconstruir los modos en que las comunidades disciplinarias intervienen en la discusión, adopción y aplicación de ideas en el Estado.

Es evidente que las distintas carteras manifiestan ataduras diversas con las profesiones que les son cercanas. A su vez, los distintos ministerios no están solos. De hecho, puede decirse que cada uno de ellos se ubica en una constelación de agencias de la administración pública de presencia e importancia variable. Siguiendo la clasificación elaborada por Joignant (2011), se puede distinguir a los ministerios del gabinete según su perfil político, social o económico. Mientras Economía ha compartido su área de acción con ministerios sectoriales (Industria, Agricultura, Obras y Servicios Públicos) o con agencias autónomas o semiautónomas de relevancia (como el Banco Central y la AFIP) - por tanto, con saberes especializados semejantes-, Interior no solo se ubica en una zona afín a la Jefatura de Gabinete y Cancillería, sino que sus altos funcionarios compiten por la "llegada" al presidente y su protagonismo en las estrategias y negociaciones políticas junto con otros hombres fuertes del Ejecutivo como los miembros de la Secretaría General de la Presidencia, la Secretaría Legal y Técnica o la agencia de Servicios de Inteligencia. Las áreas sociales, por su parte, se despliegan en carteras de gran heterogeneidad como Trabajo, Salud, Educación y Desarrollo Social, que congregan un conjunto diverso de saberes y arraigos en la vida social. 
$\mathrm{Al}$ considerar esta distinción aparecen profesiones más polivalentes y áreas más o menos exclusivistas. Si tomamos en cuenta a los 178 ministros en funciones entre 1983 y 2017, vemos que, mientras abogados y economistas avanzan sobre carteras muy diversas, los ministerios políticos son ocupados mayoritariamente por abogados (46\%), los económicos por economistas y contadores (66\%), y los sociales por una multiplicidad de profesionales, que incluye, además de abogados y economistas, a médicos sanitaristas, docentes, trabajadores sociales, politólogos, sociólogos y otros especialistas en distintas áreas de las ciencias sociales y humanas (Fuente: Base de datos del proyecto "Socio-historia del gabinete nacional", Heredia, Gené y Perelmiter). Es posible suponer que las bases epistémicas y metodológicas que caracterizan a las disciplinas predominantes en cada ministerio se trasladen a las lógicas de acción de los mismos.

El grado en que a los cuadros ministeriales se les requiere o no contar con credenciales académicas de alto rango es también un indicador del tipo de racionalidad que prima en las carteras que ocupan. Así, por ejemplo, mientras para la mayoría de los ministerios alcanza y sobra con contar con estudios universitarios de grado, en el caso de Economía se sucedieron ministros con altas calificaciones académicas (doctorados en universidades extranjeras) y autores de publicaciones en revistas especializadas y reconocidas a nivel internacional (Heredia, 2015). Ciertamente, la ciencia económica establece los principios de validez que permean las lógicas de acción de las carteras económicas con mucho mayor énfasis que otras disciplinas o profesiones en otras áreas de gobierno, aunque dicha conexión singular tenga mayor o menor intensidad según las coyunturas de gobierno.

Pero, si bien es probable que los conocimientos expertos orienten de diferente modo la acción estatal, no menos cierto es que la pregunta por la formación de los funcionarios no se responde con la mera consideración de los niveles de profesionalización de las más altas jerarquías ministeriales. El personal estatal puede corporizar destrezas relevantes a la práctica del gobierno y la gestión que resultan ajenas a la formación universitaria: el saber político, el saber burocrático o "de expediente", y, también, lo que podríamos calificar como el saber "baqueano", aquel que proviene de la relación o la pertenencia prolongada a grupos o ámbitos de regulación estatal -empresarios, dirigentes gremiales, de movimientos sociales o grupos de diversos "afectados"-. Por supuesto, la medida en que unos u otros saberes priman en los criterios mediante los cuales se llevan adelante políticas en cada área de gobierno no es menor para reconstruir el tipo de racionalidad que las caracteriza.

Con excepción del caso de Economía (donde la pregnancia profesional dentro del ministerio es relativamente fuerte y duradera), la mayoría de las agencias públicas atesora anécdotas sobre las dificultades enfrentadas por los expertos ajenos a la dinámica estatal que circunstancialmente fueron nombrados en ellas. Especialistas con altas calificaciones técnicas y reconocimiento público suelen revelarse, una vez nombrados, incapaces de comprender y conducir las agencias a las que se los destina. Gustavo Beliz constituye el ejemplo por excelencia de un ministro del Interior que, carente de apoyos, no logró avanzar en los caminos que se había trazado. Los funcionarios del Ministerio del Interior coinciden en atribuir estas dificultades a su desconocimiento de los códigos que regulan la profesión política y a su falta de destrezas para conducir el quehacer propio de dicho ministerio (Gené, 2019).

La distinción entre diversos saberes resulta particularmente relevante cuando los dispositivos y tecnologías que instituyen y median la acción estatal se construyen en estrecha relación con ellos. Evidentemente, la transversalidad de los abogados en distintas carteras de la administración central no solo se explica por la afinidad entre la profesión jurídica y la política; las leyes, los decretos, las reglamentaciones, los diversos expedientes que configuran la acción de las burocracias públicas requieren y recompensan los conocimientos jurídicos.

Ciertamente estos saberes y destrezas no se valoran del mismo modo en distintos espacios estatales y en diversos momentos históricos. Los diagnósticos elaborados mediante el contacto directo con aquello que se evalúa -una situación de pobreza o una infracción de tránsito, por ejemplo- o mediante datos estadísticos requieren destrezas diferentes. Intervenciones que automatizan regulaciones, y otras que suponen mayores márgenes de incertidumbre y negociación en el plano de la implementación, resultan en jerarquías de saberes 
diferenciales en cada ámbito de intervención. Por ejemplo, como veremos en el próximo apartado, mientras el Ministerio de Economía ha construido la legitimidad de sus acciones a partir de la idea de objetividad de un conocimiento presuntamente universal, válido para todo el mundo y todo ámbito del quehacer social, en ciertas épocas el Ministerio de Desarrollo Social ha aspirado a una validez contrapuesta, fundada en el conocimiento contextual y localizado, en la experiencia empática con el sufrimiento particular de los grupos a ser asistidos (Perelmiter, 2016).

\section{Desafíos, interlocutores y situaciones críticas de gobierno}

Dicho esto, para comprender la manera de actuar de cada cartera, su racionalidad predominante, no basta con evaluar el tipo de destrezas que caracterizan a su personal jerárquico y administrativo; es necesario también ligar estas dimensiones a los desafíos que anidan en las áreas de la vida social que regulan o a los problemas que están llamados a enfrentar. Evidentemente, la acción de los ministerios frente a distintas situaciones, como la de Economía frente a una crisis hiperinflacionaria, la del Ministerio del Interior frente a una intervención provincial, la de Desarrollo Social frente a una emergencia alimentaria, o la de Trabajo frente a una huelga general, plantea especialidades, interlocutores y estrategias diferentes. En otros términos, las racionalidades que orientan las acciones estatales se asocian a situaciones específicas que reclaman ser gobernadas, y no existen de modo desanclado o por fuera de los desafíos que enfrentan. Por eso, precisamente, son plurales. Claro que dichos desafíos no "irrumpen" de la nada, sino que se configuran en simultáneo a las respuestas que generan y al calor de tramas, a menudo conflictivas, entre diversos grupos que disputan lo que cuenta como desafío y como "buena" respuesta a los mismos.

Parte de los desafíos de gobierno podrían definirse como problemas públicos que reclaman la intervención de las autoridades en tanto revelan una discrepancia entre "los estándares sociales ampliamente compartidos y las condiciones efectivamente observadas de la vida social” (Merton, 1971, p. 799, citado por Kitsuse y Spector, 1973, p. 408). En este sentido, muchos desafíos de gobierno se precisan cuando ciertas situaciones hieren "objetivamente" la sensibilidad de la sociedad, poniendo en cuestión el orden vigente o tensionando los valores morales que la animan. Otros desafíos de gobierno, en cambio, no llegan a asumir la forma de problemas públicos, sino que corresponden a las rutinas, muchas veces inadvertidas, de la reproducción del orden social o incluso a problemas cuya respuesta requiere de acciones que rara vez toman estado público.

La amplitud y la pluralidad de las temáticas pasibles de configurar desafíos para el Estado nos alerta sobre el carácter histórico de las cuestiones que solicitan la movilización de los agentes estatales. Ciertamente algunas de ellas, como la necesidad de acuñar moneda, defender las fronteras e impartir justicia, acompañan la formación del Estado moderno y se reproducen con ajustes hasta la actualidad. Otras, en cambio, revelan a nuestros ojos profundas transformaciones: mientras en el pasado, la relación entre los géneros era juzgada relativamente "natural", inscripta en cierto equilibrio inmemorial en el seno de la familia, recientemente se produjeron cambios en la legislación y el control de la discriminación y la violencia hacia las mujeres y diversas minorías de género. Erigidas en problemas públicos, estas cuestiones pueden ocupar el centro de la escena y movilizar a distintos grupos de la sociedad, como lo hizo en 2018 la discusión de la ley de interrupción voluntaria del embarazo, o traducirse en la creación de nuevas agencias de gobierno, como el Ministerio de las Mujeres, Géneros y Diversidad, inaugurado en diciembre de 2019 (Pereyra, 2013). Asimismo, mientras en ciertos momentos estas cuestiones ganan la escena pública y revitalizan los reclamos de intervención, en otros se repliegan en un cierto letargo que permite naturalizar el orden establecido.

En suma, los desafíos de la acción gubernamental son cambiantes y, cuando asumen el estatuto de problemas públicos, suelen presentarse a las autoridades estatales formateados por el modo en que los implicados hacen inteligible la cuestión a resolver y reclaman la intervención del Estado. La sociología de los problemas públicos ha hecho grandes aportes para comprender por qué ciertas cuestiones adquieren un estatuto tal que reclama la atención pública, la intervención estatal y la adopción de medidas concretas. 
También aportaron elementos para comprender por qué, aunque sean fuente de preocupación, ciertos problemas no logran establecer la acción estatal que requieren y, por lo tanto, no llegan a convertirse en desafíos de gobierno (Best, 2008; Gusfield, 2014 y en la Argentina: Pereyra, 2013 y Kessler, 2009). Lo notable de la construcción de problemas públicos y desafíos gubernamentales es que el proceso va precisando conjuntos de implicados que, muchas veces, no habían tenido contacto directo entre sí, y, sobre todo, que no siempre comparten una misma definición de la situación.

De este modo, frente a una visión de la sociedad como un todo indiferenciado y con intereses y valores homogéneos, el análisis de las racionalidades de los distintos ministerios de cara a desafíos situados nos introduce necesariamente en el arco de interlocutores de las políticas públicas sectoriales, sus lenguajes, formas de argumentar y presionar. Así, la política financiera es impensable sin la Bolsa, los operadores bursátiles y los bancos públicos y privados; la política de seguridad indiscernible de la policía, la prefectura, las empresas privadas que participan de la protección y el control de ciertos espacios; la política de asistencia no podría, a su vez, pensarse por fuera de los numerosos efectores sociales que canalizan la ayuda y los movimientos sociales que la reclaman. Estos anillos que acompañan a las burocracias públicas no son los mismos ni tienen el mismo poder relativo en todas las carteras del Estado nacional, pero su consideración es fundamental para entender las racionalidades distintivas de cada área de gobierno.

Precisar los grupos directamente implicados en la construcción de problemas públicos y/o de la acción gubernamental no supone que todos ellos se relacionen de forma consensual, habilitando intervenciones "neutras" o "universalmente" satisfactorias por parte de las autoridades (Fraser, 1987). Por un lado, huelga decirlo, la movilización de la acción pública supone generalmente recursos, y la escasez de los mismos obliga a establecer prioridades. Además, los desafíos de gobierno no remiten exclusivamente a decisiones presupuestarias sino también a los efectos contradictorios que generan ciertos cursos de acción. En 1989-1991 era evidente para los decisores económicos que la adopción de una paridad fija con el dólar conspiraría contra la productividad del país y, muy probablemente, provocaría un alza del desempleo: pero ¿qué era entonces más importante? ¿detener la hiperinflación o proteger el trabajo de los argentinos? (Heredia, 2017).

Es por esa razón que, cuando desbordan la reproducción ampliada de ciertas rutinas, muchos de los desafíos de gobierno suelen presentarse como opciones dilemáticas (Torre, 2013). Al analizar decisiones políticas concretas en el marco de las distintas interpretaciones y propuestas que se disputan el favor de las autoridades centrales, quedan en evidencia los esfuerzos de los funcionarios por sopesar valores y objetivos contradictorios que comprometen a distintos miembros de la sociedad. Del mismo modo en que las interpretaciones se oponen por los aspectos que iluminan y los que dejan en las sombras, las acciones (y en particular las políticas) se diferencian por aquello que asumen como dato inmodificable e inexorable de la realidad y aquello a lo que, en cambio, asignan plasticidad y capacidad de adaptación. La frontera que suele establecerse entre "el" Estado y "la" sociedad esconde hasta qué punto las distintas agencias estatales expresan en su seno conflictos de valores e intereses. Y ese conflicto también permea las lógicas de acción de los ministerios, a menudo atravesadas por sus contradicciones.

\section{EXPERTISE, PRAGMATISMO Y SENSIBILIDAD EN EL GOBIERNO: ANÁLISIS DE CASOS}

Si bien existen lógicas de acción que tienden a cristalizarse e imprimir cierta dinámica a muchas carteras ministeriales, las racionalidades que funcionan en esos ministerios no existen por fuera de ciertos contextos organizacionales, históricos y políticos específicos. Atender a estas situaciones es un principio teóricometodológico que permite considerar cómo ciertos patrones sedimentan y se expanden, pero también se debilitan y retroceden. Esta sección reconstruye tres lógicas de acción diferentes, ilustrándolas en tres ministerios específicos. Tal decisión supuso delimitar distintas cronologías históricas, puesto que no necesariamente estas lógicas se manifestaron con igual intensidad en un mismo período. 


\section{El Ministerio de Economía y la racionalidad experta}

Que el ministerio de Economía haya sido un miembro relativamente estable del gabinete nacional no significa que sus áreas de intervención hayan sido siempre las mismas ni que su importancia haya sido equivalente a lo largo de toda su historia. Hasta la crisis de 1930, como en la mayor parte de los países occidentales, las carteras económicas se concentraron en la promoción del comercio y la gestión del tesoro. La economía se definía entonces como una suerte de "aritmética estatal" (Fourquet, 1980), una herramienta para la gestión ordenada de las cuentas públicas.

Los imperativos de la gran guerra, y sobre todo del ciclo iniciado en 1945, dieron una nueva misión y un nuevo impulso a esta especialidad y sus espacios dentro del aparato estatal. Con la reafirmación transformadora de los Estados se alentó la delimitación de "economías nacionales" o "mercados internos", y las ciencias económicas se expandieron para asistir a los gobiernos en sus tareas de planificación. Los economistas dejaron de limitarse al registro de los eventos contables para consagrarse al diagnóstico y la definición de políticas que permitieran lograr la modernización, el desarrollo o la independencia económica de sus países. El auge de la teoría keynesiana y el despliegue de agencias públicas diversas organizaron esta estrategia de identificación, expansión y explotación de las fuerzas productivas locales.

La persistencia de la inflación primero y el creciente endeudamiento después desplazaron el interés de autoridades y ciudadanos de la promoción del desarrollo a la estabilización de la moneda y las cuentas públicas. Fue entonces que entidades supranacionales, como los organismos internacionales de crédito, los acreedores extranjeros y las empresas multinacionales, pero también las universidades del norte, que hegemonizaban la producción de teorías económicas, propiciaron la expansión de una expertise capaz de aplicarse con mínimos ajustes a una gran diversidad de objetos y de países (Babb, 2003). Resultaba fundamental contar con una autoridad económica que velara por la estabilidad macroeconómica y participara de la correcta coordinación de los mercados globalizados.

Esta última etapa, que afirmó los llamados hacia la austeridad pública y las reformas de mercado, revirtió en cierta medida la singular inestabilidad de los funcionarios económicos en Argentina. Entre 1930 y 1976, casi ningún gobernante logró ocupar la presidencia por el mandato establecido por la Constitución Nacional (6 años). En el marco de esta altísima rotación presidencial, los ministros de Economía fueron los más inestables de todo el gabinete. Su promedio de permanencia en el cargo fue menos de 1 año, y 15 de los 50 ministros del período no lograron siquiera mantenerse en su cargo por más de 6 meses. Durante los gobiernos dictatoriales, o las administraciones civiles bajo fuerte presión militar, el puesto de ministro fue ocupado alternadamente por un reducido círculo de liberales. Por su parte, sumidos en polémicas altamente crispadas, los ministros de los gobiernos civiles sufrieron los embates cruzados de los actores sociales y políticos de su tiempo.

Si bien continuaron siendo figuras muy polémicas, la situación de los ministros de Economía se modificó sustancialmente a partir de 1976. Al tiempo que la autoridad económica se concentraba cada vez más en el Ministerio de Economía y en el Banco Central, por primera vez en décadas, José Alfredo Martínez de Hoz, Juan Vital Sourrouille, Domingo Cavallo, Roque Fernández y Roberto Lavagna permanecieron largos períodos a cargo de esta cartera. No se trató únicamente de permanencia. En contraste con sus predecesores, lograron construir equipos propios y concentrar, a través de hombres de su confianza, secretarías fundamentales del Ministerio y otras instituciones clave, como el Banco Central.

El personal y los recursos también acompañaron el ascenso del ministerio. Según Orlansky (2001), la racionalización de la administración pública, en los años noventa, derivó en una concentración del personal en ciertas áreas: la Presidencia, la Jefatura de Gabinete, el Ministerio del Interior y el de Economía. Hacia 2005, este último ministerio seguía siendo el que detentaba una proporción mayor de personal del Sistema Nacional del la Profesión Administrativa (SINAPA), casi el $30 \%$ del mismo según jurisdicción, cifra que ascendía al 37 \% si se sumaba el Ministerio de Planificación Federal (SINAPA, 2007, p. 10). 
Esta relativa fortaleza política y burocrática se correspondió con una presencia pública que superó a todas las demás carteras. Más allá del carácter discreto o estridente de los ministros considerados, hasta los años setenta, los medios de comunicación les prestaban una atención semejante o apenas mayor que a otros altos funcionarios. Desde entonces, comenzaron a concederles una visibilidad absolutamente singular. En términos cuantitativos, mientras otros ministros conservan un promedio de 2 menciones diarias en su semana de asunción, el de economía trepó de 2 en 1970 a 6 en los años 1980 para escalar a 7 en los 1990 y a 12 en el año 2000.

¿Sobre qué bases logró consolidarse esta autoridad de los economistas y de los ministros de Economía en particular? Contrariamente a los ocupantes de otras carteras que se presentan como hombres de confianza de la autoridad electa o a ministros anteriores que se destacaban por su experiencia como empresarios o representantes sectoriales, la mayoría de los ministros de Economía que se sucedieron en la cartera desde mediados de los años 1970 detentaron vías de acceso específicas. La mayoría de ellos no eran amigos ni contaban con un conocimiento personal de las autoridades que los designaron. Tampoco, exceptuando a Roberto Lavagna, y a los más efímeros Bernardo Grinspun y Erman González, poseían sólidas filiaciones en el partido del presidente. Roque Fernández, como otros funcionarios de menor rango reclutados en los equipos técnicos, había participado incluso de agrupaciones políticas opuestas al oficialismo. Del mismo modo, si bien varios de estos ministros detentaban relaciones estrechas con el empresariado, no se trataba, como en el caso de José Ber Gelbard, de representantes de entidades patronales.

Fue más bien cierto activismo y cierta consagración en el ámbito técnico-político de la economía lo que pavimentó el acceso de la mayoría de estos expertos a la alta función pública. De hecho, muchos de los planes adoptados por estos funcionarios habían sido elaborados y discutidos en centros de estudio ajenos a los partidos y las burocracias públicas. No sorprende entonces que, hacia fines del siglo XX, medios periodísticos y profesionales se permitieran apostar sobre los próximos ministros de Economía, abstrayéndose de cualquier mención a los resultados de las elecciones y/o a las preferencias de los candidatos.

Es que un corredor paralelo, con una autoridad y una legitimidad propia, pareció definirse para esta cartera en el marco del endeudamiento estatal y la globalización de los mercados. Tenuemente en los años setenta y ochenta, y de manera diáfana entre 1991 y 2001, la Argentina evidenció administraciones bicéfalas, con el ministro de Economía y el presidente con ascendencias semejantes y hasta, en ocasiones, rivales. La posesión de diplomas de posgrado en el exterior, la pertenencia a una comunidad de especialistas internacionalizada, la participación en foros técnicos y académicos de discusión de diagnósticos y políticas, los vínculos con los organismos internacionales, delimitaron un cursus honorum (paraestatal) hacia Yrigoyen 250. Estas trayectorias definían, al parecer, rasgos de personalidad específicos: la audacia, la antipatía, la intransigencia, la ininteligibilidad, la reserva, se convirtieron en atributos asociados a la solvencia y la eficacia ministerial.

La afirmación de la economía como dominio autorregulado y el poder alcanzado por los ministerios de Economía dentro de los planteles gubernamentales de los países más débiles y endeudados (Schneider, 1998; Hira, 2007) son indisociables de la consolidación de la ciencia económica como disciplina científica unificada a nivel global. Desde los años setenta, las ciencias económicas lograron asemejarse cada vez más a las ciencias naturales y exactas: la teoría neoclásica se afirmó como marco de la mayoría de las producciones académicas y la econometría desplazó a las argumentaciones en prosa como modo de enunciación y validación de conocimientos (d'Autume y Cartelier, 1995). Mientras que, en los años setenta, todavía seguía vigente la controversia entre enfoques monetaristas y keynesianos, dos décadas más tarde la teoría neoclásica se había consolidado como marco analítico hegemónico en todo Occidente. Al recubrir a la mayor parte de los profesionales, los economistas "liberales" se habían convertido en economistas a secas y sus supuestos, en el fundamento de gran parte de la racionalidad formal prevaleciente en el mundo occidental (Heredia, 2015).

Cierto, en Argentina tras la debacle de 2001 y sobre todo después de la salida de Roberto Lavagna en 2005, la suerte del ministerio fue otra; el alza de la inflación y el modo en que la problemática fue decodificada por los principales interlocutores de la autoridad económica propiciaron, no obstante, cierto 
retorno a carteras económicas fuertes. Luego de 2003, un conjunto de indicios manifiesta la "repolitización" de la cartera económica: se pluralizaron los especialistas y las perspectivas ideológicas que participaron del debate "económico", regresaron al gabinete los ministerios productivos, se sucedieron varios ocupantes en la cartera, muchos de los cuales carecieron de toda presencia pública, se disgregó el poder concentrado en la figura del ministro y hasta figuras ajenas a Economía resultaron relevantes en la conducción del crecimiento, la distribución y la estabilidad. Más tarde, sin embargo, se revirtieron muchas de esas tendencias. Con la desaceleración del crecimiento y la inestabilidad cambiaria, los economistas profesionales y los organismos internacionales volvieron a monopolizar la opinión económica en los medios de comunicación, al tiempo que la inflación volvió a afirmarse como principal desafío de la gestión gubernamental, tanto en el segundo mandato de Cristina Fernández de Kirchner como durante toda la presidencia de Mauricio Macri (Heredia y Gaillardou, 2017).

\section{El ministerio del Interior y la racionalidad pragmática}

El Ministerio del Interior constituye un espacio particular dentro del gabinete nacional. Por un lado, tiende a ser poco conocido y muchas de sus tareas parecen ser elusivas para la opinión pública en general. Por el otro, desde los inicios del Estado nación ocupó un lugar central en el sistema político y se reveló como fundamental para sus propios participantes. Caracterizado como el "organismo político por excelencia" dentro del Poder Ejecutivo (Oszlak, 2000, p. 5), dicho ministerio se ha dedicado tradicionalmente a articular vínculos con los gobernadores provinciales y distintos actores de los estados subnacionales, así como con los principales referentes de los partidos políticos en el Congreso y otros espacios de representación. Asimismo, funcionó casi invariablemente como vocero del gobierno ante los medios de comunicación, al menos hasta la creación de la Jefatura de Gabinete.

De acuerdo a la Ley de Ministerios $n^{\circ} 26.338 / 2007$ y sus modificaciones, esta cartera posee una responsabilidad determinante en el gobierno político interno y el resguardo del régimen republicano, representativo y federal. En particular, tiene a su cargo las relaciones con los gobiernos provinciales y ejecuta la intervención del gobierno federal en las provincias en estado de crisis, ${ }^{6}$ además de organizar las elecciones y controlar el financiamiento de los partidos políticos. Tradicionalmente, el Ministerio del Interior estuvo a cargo de la seguridad interna y el manejo de las fuerzas de policía, aunque esta responsabilidad histórica se vio alterada a lo largo del tiempo. En la actualidad, existe un ministerio específico que alberga a la policía federal -el Ministerio de Seguridad, creado en 2010-, pero históricamente su manejo fue atribuido al Ministerio del Interior, que encontró en esa función una parte sustancial de su magnitud y la envergadura de su presupuesto. Finalmente, en un plano menos político y más rutinario, el ministerio expide los documentos nacionales de identidad, centraliza las estadísticas demográficas de todo el país y controla los flujos migratorios. Este carácter amplio de sus funciones y el contraste entre las responsabilidades más estables de la administración pública y las más estrechamente ligadas a la coyuntura política fueron sedimentando lógicas de acción fuertemente diferenciadas en su seno. En lo que refiere a sus primeras y segundas líneas, la racionalidad estratégico-política se reveló constante y eficaz para atravesar sus principales pruebas.

¿Con qué herramientas ha contado este ministerio y cómo dilataron o constriñeron sus márgenes de acción sus ocupantes? Durante la década del noventa, en plena reforma del Estado, la cartera de Interior creció tanto en términos relativos como absolutos (Orlansky, 1995). Por un lado, tuvo la responsabilidad, junto con el Ministerio de Economía, de negociar los pactos fiscales con las provincias (Falleti, 2004), y, por otro, detentó el manejo de una cantidad importante de recursos económicos a través de los controversiales Aportes del Tesoro Nacional (ATN). El manejo de este recurso es particularmente ilustrativo de la racionalidad que prima en esta cartera, pues abre vías de negociación directa entre actores políticos subnacionales y el Estado central, dejando un amplio margen de acción para que este último requiera compromisos especiales 
por parte de sus interlocutores. Se trata de un fondo creado por ley en 1988, que representa el $1 \%$ de los recursos coparticipables y que el Estado nacional, a través del Ministerio del Interior, tuvo la responsabilidad de repartir entre las provincias según lo que identificara como "situaciones de emergencia y desequilibrios financieros de los gobiernos provinciales" (Boletín Oficial, 26/01/1988). Así, los famosos y a menudo sospechados ATN representaron prendas de negociación política con los poderes territoriales, vehiculizando a la vez asistencia, persuasión y cooptación en la relación entre el Estado central y las provincias.

De este modo, el Ministerio del Interior conjugó atribuciones burocráticas estables y regulares con el trabajo político y la construcción de poder del partido de gobierno. Esto es así porque en un nivel menos formalizado esta cartera también gestiona la negociación de leyes importantes para el Poder Ejecutivo con los representantes de las dos cámaras del Congreso, funciona como mediación de múltiples acuerdos entre los partidos mayoritarios, intenta instalar y legitimar la agenda de gobierno ante los medios de comunicación, y se ocupa de construir alianzas y asegurar apoyos de cara a las elecciones, o bien busca garantizar la gobernabilidad en tiempos de crisis (Gené, 2019).

En este sentido, sus funciones, ámbitos de intervención e interlocutores lo hacen un espacio fuerte de la política, un ministerio que a la vez mide el pulso político y apuesta a generarlo. En virtud de tales características, las lógicas de acción que predominan en el ministerio son sensiblemente diferentes a las que caracterizan a la cartera económica, y las credenciales detentadas por sus primeras y segundas líneas también son específicas y diferentes a las de otras agencias de gobierno. En términos generales, podemos decir que, más allá de las diferencias de protagonismo de sus miembros a lo largo del tiempo, sus desafíos e interlocutores hicieron que en este espacio se privilegiaran de modo persistente la trayectoria y la destreza políticas, la pericia para la negociación, el pragmatismo y la astucia para las estrategias. En este sentido, lejos de fundar su expertise en títulos universitarios o vínculos internacionales, los ocupantes del ministerio pusieron en práctica saberes aprendidos en sus largos itinerarios en el mundo de la política, hechos de reglas tácitas y códigos informales, que sirvieron para vincularlos entre sí y lograr acuerdos en distintas escalas.

En primer lugar, la cercanía y la confianza con el presidente constituyen elementos centrales para explicar el poder de un ministro político. Aquella "llegada" al primer mandatario y la relativa autonomía que la misma otorga puede expresarse en distintos indicadores, que los políticos en este ministerio saben ejercer y sus interlocutores saben medir: la posibilidad (o no) de designar a sus propios equipos en las secretarías y subsecretarías a su cargo, el manejo "efectivo" de los resortes de poder que corresponden a la cartera y la participación en la "mesa chica" de las decisiones son algunos de ellos. Otro de los signos distintivos de los miembros jerárquicos de este ministerio es su conocimiento íntimo de los actores y los mecanismos de funcionamiento del universo político. Dado que el principal desafío de Interior reside en la negociación con actores de diversos niveles y signos partidarios, comprender las reglas y manejar los códigos tácitos de estos sistemas de relaciones fue casi invariablemente un requisito primordial para conducir esta cartera. Sin gran sorpresa entonces, su reclutamiento se operó consistentemente al interior de los partidos políticos, recurriendo a dirigentes con extensas trayectorias, iniciadas en la militancia juvenil y continuadas con múltiples cargos electivos y de designación política en distintos niveles de gobierno. ${ }^{7}$

Destreza central en el ministerio político, la habilidad para la negociación encuentra sus condiciones de posibilidad en la autoridad frente a los interlocutores para ejercer el poder y en la capacidad de inspirar su confianza y mantenerla en el tiempo. Ya no se trata sólo de la confianza presidencial, sino además de aquella que otorgan los pares. En un ministerio donde numerosos acuerdos se llevan a cabo de manera informal, o incluso secreta, la confianza deviene esencialmente un reductor de incertidumbre. Según la célebre formulación de Simmel (2010 [1908], p. 356), la confianza es "una hipótesis sobre una conducta futura", que permite prever con mayor o menor certeza las conductas de los otros y fundar las propias prácticas sobre la base de esas expectativas. La capacidad de alcanzar acuerdos informales descansa, entonces, sobre este conocimiento recíproco y el saber que otorga sobre las posibles acciones por venir. 
El carácter confiable o no de los cuadros de este ministerio para sus interlocutores fue central en su desempeño y suscitó evaluaciones compartidas entre aliados y adversarios, fundando reputaciones con claros efectos prácticos como las de "leal" o "traidor", "con o sin códigos", "cumplidor" o "amateur". Por lo general, dichas consideraciones no se encontraron en sintonía con las expresadas por periodistas u otros observadores de la dinámica política. Sin embargo, los presidentes privilegiaron recurrentemente estos perfiles, lo que confirma su capacidad para resolver cierto tipo de problemas y atravesar las pruebas que atañen especialmente a este ministerio (Gené, 2018).

Otras capacidades destacadas en esta cartera son las de movilizar apoyos y lealtades en distintos puntos del territorio y la habilidad para definir estrategias frente a la incertidumbre. En tiempos de inestabilidad institucional o crisis políticas, distintos ensamblajes son posibles frente al desafío de garantizar la gobernabilidad, y el Ministerio del Interior tuvo un rol preponderante a la hora de idearlos y llevarlos a la práctica. Así, la competencia para amalgamar acuerdos y controlar escenarios conflictivos fue especialmente reconocida en esta cartera política. Poder gestionar las crisis y prever estrategias alternativas cuando las opciones disponibles no abundan constituyó una de las destrezas menos "técnicas" pero más "racionales" desplegadas en este espacio. En este sentido, la experiencia política y los contactos asiduos con referentes y "armadores" de todos los partidos fueron y siguen siendo recursos centrales para sus ocupantes, en tanto habilitan la ductilidad y la racionalidad pragmático-estratégica que caracteriza a este ministerio.

\section{El ministerio de Desarrollo Social y la racionalidad sensible}

Desde la recuperación de la democracia, conforme la pobreza se consolidaba como problema público, las áreas asistenciales del Estado adquieren una creciente relevancia pública. Sin embargo, será recién en 1999, con el gobierno de De la Rúa, que la política asistencial, entendida como política de "desarrollo social", alcanzará rango ministerial: la Secretaría de Desarrollo Social, creada en 1994, se transformará entonces en ministerio. En este sentido, la cortísima historia de la cartera "de la pobreza" contrasta fuertemente con la del Ministerio de Economía e Interior, que integran el gabinete nacional desde larga data. Esta juventud institucional y antes el carácter errático de la evolución de la asistencia en el aparato estatal (Tenti Fanfani, 1989; Repetto, 2014) son relevantes para comprender sus lógicas de acción predominantes.

Otros dos rasgos de la política asistencial son importantes para entender las lógicas de acción del área. En primer lugar, la asistencia es una actividad sobre la cual el Estado nunca ha detentado el monopolio conceptual y procedimental. Su ejercicio ha sido recurrentemente delegado en los gobiernos subnacionales o en diversas organizaciones sociales como la Iglesia. Al no contar con dispositivos históricamente asentados de intervención -como escuelas u hospitales- la densa red de mediadores que ponen a funcionar la asistencia dispersa los criterios para la asignación de beneficios. Del mismo modo, la hacen más dependiente de compromisos locales y circunstanciales en la definición de esos criterios. La carencia de "efectores propios" es, además, consustancial a ciertas dificultades para estandarizar modos de intervención en el territorio. No menos relevante, en segundo lugar, es que la asistencia es un área bajo un singular escrutinio público. Percibida como instrumento de "paternalismo", "clientelismo" o "estigmatización", sus lógicas de acción se comprenden, a menudo, como respuestas a las potenciales acusaciones políticas y morales que los dispositivos de intervención pueden acarrear. Esto refuerza su intensa vulnerabilidad a la coyuntura, y explica, en parte, el peso que adquieren los aspectos escénicos de su intervención (Perelmiter, 2016).

Hasta el 2003, la inestabilidad de las estructuras y políticas de asistencia en el Estado se manifestó también en la de su personal. Históricamente, el carácter espasmódico de las entradas y salidas de altos funcionarios y cuadros medios dificultó el establecimiento de experiencias de gestión que pudieran institucionalizarse. En ese marco, una excepción fue la gestión de Eduardo Amadeo, secretario de Desarrollo Social entre 1994 y 1998, que desplegó un cambio en las lógicas de acción del área. Economista, especialista en políticas sociales, conectado con los organismos internacionales de crédito y político peronista, fue un ejemplo paradigmático 
de una nueva figura: el "gerente social” (Pantaleón, 2005). Amadeo y la Secretaría encarnaron una modalidad de gestión en línea, al menos desde lo retórico, con la "racionalidad experta" que primaba en las áreas económicas del Estado y que se tradujo en los dispositivos de intervención asistencial que proliferaron desde entonces por todo el gabinete nacional: los programas sociales focalizados (Grassi, 2003). El área conoció entonces el ascenso de los expertos y un proceso de especialización académica vertiginoso, que no bastó, sin embargo, para unificar y cohesionar los perfiles y destrezas valoradas para "gestionar la asistencia" (Vommaro, 2012).

Pero el cambio más significativo se dio a partir de 2003, con la gestión de Alicia Kirchner, que ocupó la cartera hasta 2015. Su gestión configuró una “época”, consolidó institucionalmente al ministerio, expandió su infraestructura y estabilizó líneas de intervención que continuaron incluso durante el gobierno de Cambiemos. En efecto, frente el gran desafío que supuso la emergencia social que sobrevino a la crisis de 2001, la distribución de beneficios se masificó. De la mano de una sostenida holgura fiscal, entre 2003 y 2009 el presupuesto de la cartera se quintuplicó, y llegó a ser uno de los más importantes del gabinete nacional (Oficina Nacional de Presupuesto, Secretaría de Hacienda, Ministerio de Economía de la Nación) A la par del aumento de los recursos, sus estructuras institucionales se expandieron, tanto a nivel central como territorial. La creación de una red de oficinas de nivel provincial y municipal permitió anclar y autonomizar su intervención en el nivel local, lo que proveyó a la asistencia nacional de una infraestructura territorial de la que antes carecía ${ }^{8}$ (Perelmiter, 2017).

Como en otras áreas de intervención estatal, gran parte de los saberes asistenciales se forman, acreditan y ponen a prueba en el quehacer cotidiano de gobierno, en la capacidad de responder a los desafíos que se presentan en ese quehacer, traduciendo demandas sociales en acción pública. Atendiendo a ese nivel práctico de la acción estatal, y contra la tendencia a ubicar los saberes de Estado exclusivamente en la tensión entre técnica y política, el caso de la asistencia evidencia una tercera dimensión fundamental: los aspectos sensibles o estéticos de la gestión pública, su puesta en escena. En los años posteriores a la crisis de 2001 esta dimensión adquirió una relevancia singular.

En efecto, la construcción de un Ministerio "sensible”, cultor de cercanía social, permeó el estilo de gestión de Alicia Kirchner, de una gran parte del personal ministerial y de los dispositivos organizacionales de intervención (Perelmiter, 2012a). La actualización del imaginario "evitista" de la asistencia ${ }^{9}$, la reivindicación de un ethos del sacrificio, la consagración de la acción urgente y el voluntarismo caracterizaron la narrativa institucional del organismo y organizaron gran parte de sus acciones concretas, acciones que se entretejieron con los dispositivos técnicos de gestión social. Estos dispositivos, como las transferencias monetarias condicionadas, ganaron cada vez más relevancia en los modos de atender la pobreza, sobre todo a partir del 2009, con la creación de la Asignación Universal por Hijo. Aun así, el Ministerio de Desarrollo Social continuó recreando una lógica de acción sensible. De hecho, las estrategias de territorialización institucional aspiraron a este tipo de validez: se trataba de "salvar distancias", de "embarrarse", de hacerse presente "ahí", en el lugar de los padecimientos.

Si comúnmente se esperan de la burocracia estatal acciones orientadas por la impersonalidad formalista, en este caso se esperó en cambio empatía con el sufrimiento de los pobres. La validez de estas intervenciones se fundó así en un juicio que no sólo reclamaba eficacia objetiva y rectitud normativa, sino también, sobre todo, autenticidad. Autenticidad que se acreditaba (o no) en los aspectos escénicos y mundanos del quehacer cotidiano: el empeño en "resolver" demandas de personas particulares, la disposición a trabajar más allá de las incumbencias formales, el buen trato, la voluntad de entrar en contacto directo con las personas en situación de pobreza, de escuchar sus historias singulares, de justificar excepciones a las normas en función de esas historias.

Lo curioso es que, con este horizonte, el Ministerio profesionalizó a su funcionariado. Entre 2003 y 2007 , la cartera triplicó su plantel de trabajadores sociales. La decisión de construir una burocracia enraizada al territorio, en condiciones de disputar cercanía y afectividad en el vínculo asistencial, estuvo en la base del 
proceso de valorización -simbólica y salarial- del trabajo social en la práctica ministerial. La jerarquización en el Estado central de actores asociados a la operatoria local de la asistencia, de una destreza experiencial más del caso que de la cifra- resultó afín al tipo de autoridad que se buscaba (Perelmiter, 2012a).

La misma aspiración, por otra parte, significó el reclutamiento de militantes de base en el organismo y la integración de organizaciones de desocupados a la gestión, actores también capaces de dotar de compromiso sensible a la asistencia nacional (Perelmiter, 2012b). La racionalidad sensible, que aspira a la autenticidad del compromiso afectivo en la acción estatal, no fue solo una preferencia de las elites de gobierno o una actualización de la tradición evitista de la asistencia. En el contexto argentino de 2003, respondía también a las demandas que pesaban sobre un centro de poder muy frágil, imputado por "indiferencia" y "abandono" de las poblaciones y territorios más postergados del país. Para esta cartera, ganar proximidad social, dotar de sensibilidad su intervención, fue un desafío técnico y político de primer orden durante y después de la emergencia social.

En suma, la racionalidad sensible que caracterizó las lógicas de acción de esta cartera durante el kirchnerismo se comprende sobre todo de cara a la historia institucional y cultural del área asistencial. No menos cierto es que la coyuntura de crisis aguda que enfrentó la Argentina en 2001 precipitó la pregnancia organizacional de la misma. Más tarde, durante la gestión de Cambiemos, el ministerio mixturó perfiles y atributos de gestión propios de la gerencia social y del saber-hacer de los políticos peronistas, dando continuidad a algunas de las principales políticas del ciclo anterior e intentando responder con nuevas retóricas y dispositivos al desafío de acortar las distancias y poner en escena a la sensibilidad como razón de Estado (Salerno, 2019).

\section{A MODO DE CIERRE}

Tanto las interpretaciones que critican el carácter decisionista o hiperpresidencialista del modo de gobernar la Argentina (Bosoer y Leiras, 1999; Novaro, 2001; Quiroga, 2007) como las que reclaman una mayor eficacia en el ejercicio de la función presidencial tienden a compartir un mismo supuesto: que existe un centro del que parte la autoridad pública y que el mismo podría o debería resolver los distintos desafíos de gobierno apelando a los resortes burocráticos como meras herramientas de gestión.

Sin desmerecer las preocupaciones por el apego a las reglas y la eficacia técnico-administrativa, la reconstrucción de las racionalidades estatales que hemos propuesto en este trabajo intenta comprender a los ministerios como espacios de mediación del quehacer del gobierno central, y, para hacerlo, avanza en el estudio de tres focos conceptuales: los actores con pregnancia en las organizaciones estatales y sus atributos, los escenarios institucionales que los abrigan y por los que circulan, y los desafíos de gobierno que enfrentan en determinadas coyunturas históricas. De esta manera, se asume tanto la necesidad de no homogeneizar a los gobiernos y al Estado como la necesidad de advertir que la autoridad pública no se reduce a los atributos de los grupos que ocupan sus principales jerarquías. Este punto de partida resulta tanto más relevante cuanto que la lógica de funcionamiento de las posiciones gubernamentales y estatales, independientemente de quienes las dirigen, pueden definir marcos de valoración y pruebas de eficacia que no necesariamente coinciden con aquellos propios de otros ámbitos, como el académico, el partidario o el mercantil.

Primero, es importante hacer una distinción entre tecnificación y racionalización estatal. Incluso si nos atenemos a una definión muy modesta de formación, las tres carteras estudiadas corroboran que los altos funcionarios públicos argentinos suelen tener estudios universitarios, pero también evidencian la diversidad de sus disciplinas de origen: en el ministerio de Economía predominan contadores y economistas, en Interior dominan los abogados, y en Desarrollo Social se observa una pluralidad de graduados universitarios con diplomas dispersos.

Pero el argumento aquí desarrollado intentó ir más allá. La orientación de la acción cuya pretensión de validez, para utilizar el lenguaje habermasiano, se funda en la adecuación de medios y fines de cara a un 
mundo objetivo, no agota las acepciones múltiples que, en la tradición sociológica desde Max Weber en adelante, adquiere la noción de racionalidad. Si la racionalidad instrumental comúnmente asociada a la técnica no caracteriza la totalidad de la práctica estatal, y tampoco cubre los diversos principios de autoridad que reclaman los actores estatales, habrá que buscar qué otras racionalidades la orientan, en qué coyunturas y áreas de intervención y por qué motivos razonables (Heredia, 2017). Clasificar las organizaciones y actores estatales en "racionales" e "irracionales" define como residuales prácticas estatales habituales, que merecen una atención equivalente a la que reciben aquellas calificadas como "normales" por la literatura. Reconstruir las aspiraciones de validez que comportan las prácticas estatales y que delimitan destrezas diferenciales en su vida organizacional constituye un paso necesario, a nuestro juicio, para acercarnos al "régimen de racionalidades" del Estado, más denso y complejo que las dicotomías con las que suele caracterizárselo: "racional" e "irracional", "profesional" o "político", "especializado" o "amateur".

En este sentido, las pretensiones de validez de cada área del quehacer estatal son indisociables de los problemas que enfrentan y de los interlocutores que, desde el llano, contribuyen a configurarlos antes y después del mandato de cada ministro. Aun cuando se trate de una emergencia, no es lo mismo resolver una corrida cambiaria que una intervención federal o una asistencia alimentaria de urgencia. Incluso cuando la acción estatal intente unificarse para dar respuesta a una misma situación crítica -como la pandemia de la Covid 19 en 2020-, las tareas y pruebas de gestión que enfrentarán el ministerio económico, el político y el social serán bien diferentes. Del mismo modo, más allá de sus orígenes, formaciones y trayectorias, los ministros económicos se verán obligados a interactuar con empresarios, banqueros y dirigentes de organismos internacionales, los del Interior deberán hacerlo con gobernadores, dirigentes de la oposición y periodistas, y los del área social tendrán que construir una relación y preferentemente un vínculo de confianza con miembros de la Iglesia católica, los movimientos sociales y las organizaciones de la sociedad civil.

En suma, las lógicas de acción ministeriales deben ser comprendidas socio-históricamente por una constelación de factores entre los que se cuentan los saberes y destrezas de su personal, la impronta del presidente, las características del partido de gobierno o el peso de sus diversas líneas internas, los desafíos específicos enfrentados en la coyuntura y las etapas atravesadas por las distintas administraciones. A todos ellos se suman, además, las características y responsabilidades singulares de cada cartera. Hemos insistido en que, por sus interlocutores y por sus pruebas, los recursos y las competencias susceptibles de valorizarse en cada ministerio son bien diferentes. Por lo tanto, además de preguntarse por la existencia (o no) de una lógica común que guía a la autoridad pública, es conveniente indagar en los rasgos distintivos de cada cartera de gobierno, en su historicidad y sus modos de ejercer la autoridad para comprender el carácter múltiple y, solo eventualmente convergente, de la racionalidad estatal.

\section{ReFERENCiAS}

Alcántara, M. (2012). El oficio de político. Madrid: Editorial Tecnos.

Amorim Neto, O. (2006). The Presidential Calculus. Executive policy making and cabinet formation in the Americas. Comparative Political Studies, 39(4), 415-440.

Babb, S. (2003). Proyecto México. Los economistas del nacionalismo al neoliberalismo. México DF: Fondo de Cultura Económica.

Barry, C.; Ramaccioti, K. y Valobra, A. (eds.) (2008). La Fundación Eva Perón y las mujeres: entre la provocación y la inclusión. Buenos Aires: Biblos.

Beltrán, G. (2005). Los intelectuales liberales: poder tradicional y poder pragmático en la Argentina reciente. Buenos Aires: Eudeba-Libros del Rojas.

Best, J. (2008). Social Problems. New York-London: Norton.

Bohoslavsky, E. y Soprano, G. (2010). Un Estado con rostro humano. Funcionarios e instituciones estatales en Argentina (desde 1880 hasta la actualidad). Los Polvorines: UNGS-Prometeo. 
Bosoer, F. y Leiras, S. (1999). Postguerra fría, decisionismo, neodecisionismo y nueva fase del capitalismo. En A. Borón (ed.), Tiempos violentos (pp. 171-195). Buenos Aires: Eudeba.

Camerlo, M. y Coutinho, M. (2019). Ministros y afiliación partidaria. Propuesta metodológica aplicada al caso argentino. América Latina Hoy, 81, 99-118.

Camerlo, M. (2013). Gabinetes de partido único y democracias presidenciales. Indagaciones a partir del caso argentino. América Latina Hoy, 64, 119-142.

Camerlo, M. y Pérez Liñán, A. (2012). Presidential approval and democratic survival. Ponencia presentada en la American Political Science Association Annual Meeting. Estados Unidos, Nueva Orleans.

Camerlo, M. (1990). Political Careers and Minister Turnover under Presidentialism. Lisboa: University of Lisbon.

Camou, A. (1998). Saber técnico y política en los orígenes del menemismo. Perfles Latinoamericanos, 12, 85-107.

Canelo, P. (2012). 'Un ministerio de tercera línea'. Transformaciones en el reclutamiento y las trayectorias de los Ministros de Defensa argentinos. Polhis, 5(9), 319-329.

Centeno, M. y Silva, P. (1998). The politics of expertise in Latin America. New York: St. Martin's Press.

d'Autume, A. y Cartelier. J. (eds.) (1995). L'économie devient-elle une science dure?. París: Economica.

De Imaz, J. L. (1964). Los que mandan. Buenos Aires: Eudeba.

De Luca, M. (2011). Del príncipe y sus secretarios. Cinco apuntes sobre gabinetes presidenciales en la Argentina reciente. En A. Malamud y M. De Luca (coord.), La politica en tiempos de Kirchner (pp. 37-48). Buenos Aires: Eudeba.

Dezalay, Y. y Garth, B (2002). La mondialisation des guerres de palais. Paris: Seuil.

Escobar-Lemmon, M. y Taylor-Robinson, M (2009). Getting to the Top: Career Paths of Women in Latin American Cabinets". Political Research Quarterly, 62(4), 685-699.

Falleti, T. (2004). Federalismo y descentralización en Argentina. Antecedentes históricos y nuevo escenario institucional de las relaciones intergubernamentales. En A. Clemente y C. Smulovitz (dir.), Descentralización, politicas sociales y participación democrática en Argentina (pp. 7-38). Buenos Aires: IIED-AL.

Ferreira Rubio, D. y Goretti, M. (2000). Argentina 2000: Politics, Economy, Society and International Relations. Oxford: University of Oxford.

Ferreira Rubio, D. y Goretti, M. (1996). Cuando el presidente gobierna solo. Menem y los decretos de necesidad y urgencia hasta la reforma constitucional (julio 1989-agosto 1994). Desarrollo Económico, 36(141), 443-474.

Fourquet, F. (ed.) (1980). Les comptes de la puissance: histoire de la comptabilité nationale et du plan. París: Encres.

Fraser, N. (1987). Women, Welfare and the Politics of Need Interpretation. Thesis Eleven, 17, 88-106.

Gené, M. (2019). La rosca política. El oficio de los armadores delante y detrás de escena (o el discreto encanto del toma y daca). Buenos Aires: Siglo XXI.

Gené, M. (2018). El trabajo de los armadores políticos en Argentina: desafíos, instrumentos y competencias para el detrás de escena. Iconos. Revista de Ciencias Sociales, 60(22), 57-80.

Gené, M. (2012). Negociación política y confianza. El Ministerio del Interior y los hombres fuertes del Poder Ejecutivo. Polhis, 5(9), 301-308.

Giorgi, G. (2014). Ministros y ministerios de la Nación: un aporte prosopográfico para el estudio del gabinete nacional (1854-2011). Apuntes, Revista de Ciencias Sociales de la Universidad del Pacifico, 41(74), 103-139.

Giorgi, G. (2020). El expertise como recurso político. Credenciales, redes y alta gestión estatal en Desarrolllo Social de la Nación en las décadas de 1990 y 2000. Trabajo y Sociedad, 21(34), 23-47.

Gusfield, J. (2014). La cultura de los problemas públicos. El mito del conductor alcoholizado versus la sociedad inocente. Buenos Aires: Siglo XXI.

Grassi, E. (2003). Politicas y problemas sociales en la sociedad neoliberal: la otra década infame. Buenos Aires: Espacio Editorial.

Habermas, J. (1999). Teoría de la acción comunicativa. Tomo I. Madrid: Taurus. 
Heredia, M. y Gaillardou, F. (2017). El debate económico. Del consenso a la antinomia. En A. Pucciarelli y A. Castellani (coords.), Los años del kirchnerismo. La diputa hegemónica tras la crisis del orden neoliberal (pp. 209-237). Buenos Aires: Siglo XXI.

Heredia, M. (2017). Política y decisión: La razonabilidad de la acción política a través de la historia de la convertibilidad. En G. Vommaro y M. Gené (comps.), La vida social del mundo político: investigaciones recientes en sociología politica (pp. 189-209). Buenos Aires: Ediciones UNGS.

Heredia, M. (2015). Cuando los economistas alcanzaron el poder. O cómo se gestó la confianza en los expertos. Buenos Aires: Siglo XXI.

Heredia, M. (2012). La ciencia global en el gabinete nacional. El singular ascenso del Ministerio de Economía. Polbis, 5(9), 291-300.

Hira, A. (2007). Should economists rule the Word? Trends and implications of leadership patterns in Developing World, 1960-2005. International Political Sciences Review, 28(3), 325-360.

Joignant, A. (2011). Tecnócratas, technopols y dirigentes de partido: tipos de agentes y especies de capital en las elites gubernamentales de la Concertación (1990-2010). En A. Joignant y P. Güell (comps.), Notables, tecnócratas y mandarines (pp. 185-202). Santiago de Chile: Universidad Diego Portales.

Kessler, G. (2009). El sentimiento de inseguridad. Sociología del temor al delito. Buenos Aires: Siglo XXI.

Kitsuse, J. y Spector, M. (1973). Towards a Sociology of Social Problems: Social Conditions, Value-Judgements and Social Problems. Social Problems, 20(4), 407-419.

Markoff, J. y Montecinos, V. (1994). El irresistible ascenso de los economistas. Desarrollo Económico, 133(34), 3-29.

Martinez-Gallardo, C. (2011). Designing Cabinets: Presidential Politics and Cabinet Instability in Latin America. Kellogg Institute for International Studies - Working Paper, 375.

Martinez-Gallardo, C. (2012). Out of the cabinet: What drives defections from the government in Presidential Systems?. Comparative Political Studies, 45(1), 62-90.

Martínez Nogueira, R. (2013). La presidencia y las organizaciones estatales como constructoras de institucionalidad en la Argentina. En C. Acuña (comp.), ¿Cuánto importan las instituciones? (pp. 71-119), Buenos Aires: Siglo XXI-Osde.

Morresi, S. y Vommaro, G. (comps.) (2012). Saber lo que se hace. Expertos y politica en la Argentina reciente. Buenos Aires: Prometeo.

Novaro, M.; Bonvecchi, A. y Cherny, N. (2014). Los límites de la voluntad. Los gobiernos de Duhalde, Néstor y Cristina Kirchner. Buenos Aires: Ariel.

Novaro, M. (2001). El presidencialismo argentino entre la reelección y la alternancia. En I. Cheresky y I. Pousadela (comps.), Politica e instituciones en nuevas democracias latinoamericanas (pp. 59-108). Buenos Aires: Paidós.

Ollier, M.y Palumbo, P. (2016). ¿Caso testigo o caso único? Patrones de la formación de gabinete en el presidencialismo argentino (1983-2015). Colombia Internacional, 87, 53-80.

Orlansky, D. (2001). Política y burocracia. Documentos de trabajo del IIGG, 26, 6-7.

Orlansky, D. (1995). Crisis y transformación del Estado en la Argentina (1960-1993). Cuaderno de Estudios Empresariales, 5, 375-403.

Oszlak, O. (2000). El mito del Estado mínimo: Una década de reforma estatal en la Argentina. IV Congreso Internacional del CLAD sobre Reforma del Estado y de la Administración Pública, Santo Domingo.

Oszlak, O. (1979). Notas críticas para una teoría de la burocracia estatal. Desarrollo Económico, 19(74), 211-250.

Pantaleón, J. (2005). Entre la Carta y el Formulario. Politica y técnica en el Desarrollo Social. Buenos Aires: Antropofagia.

Perelmiter, L. y Paura, V. (2019). Los ministros del trabajo y la pobreza en democracia. Entre arraigos sociales, vínculos políticos y desafíos de gestión. En P. Canelo y M. Heredia (comps.), Los puentes y las puertas. Las fronteras de la politica argentina a través de sus elites (pp. 181-207). Buenos Aires: UNSAM Edita.

Perelmiter, L. (2017). Ganar proximidad. Estado, territorio y gestión social en los años kirchneristas. En A. Pucciarelli y A. Castellani (comps.), Los años del kirchnerismo (pp. 267-292). Buenos Aires: Siglo XXI. 
Perelmiter, L. (2016). Burocracia plebeya: la trastienda de la asistencia social en el Estado argentino. Buenos Aires: UNSAM Edita.

Perelmiter, L. (2012a). Saber asistir: técnica, política y sentimientos en la asistencia estatal. Argentina (2003-2008). En S. Morresi y G. Vommaro (comps.), Saber lo que se hace. Expertos y política en la Argentina reciente (pp. 135-170). Prometeo: Buenos Aires.

Perelmiter, L. (2012b). Fronteras inestables y eficaces. El ingreso de organizaciones de desocupados a la burocracia asistencial del Estado. Argentina (2003-2008). Estudios Sociológicos, 89, 431-458.

Pereyra, S. (2013). Política y trasparencia. La corrupción como problema público. Buenos Aires: Siglo XXI.

Plotkin, M. y Zimmermann, E. (comps.) (2012). Los saberes del Estado. Buenos Aires: Edhasa.

Pomares, J., Leiras, M., Page, M., Zárate, S. y Abdala, M. (2014). Los caballeros de la mesa chica. La lógica de designación de los gabinetes desde 1983. Documentos de Politicas Públicas del CIPPEC 139. Buenos Aires: CIPPEC.

Quiroga, H. (2007). La arquitectura del poder en un gobierno de la opinión pública. En I. Cheresky (comp.), La politica después de los partidos (pp. 75-99). Buenos Aires: Prometeo.

Quiroga, H. (2005). La Argentina en emergencia permanente. Buenos Aires: Edhasa.

Repetto, F. (2014). Políticas sociales: una mirada político-institucional a sus reformas, desafíos e impactos. En C. Acuña (comp.), El Estado en acción. Fortalezas y debilidades de las politicas sociales en Argentina (pp. 19-69). Buenos Aires, S. XXI y Fundación OSDE.

Salerno, A. (2020). La cara social de la nueva derecha. Perfiles politicos, atributos de gestión socio-asistencial del PRO y de Cambiemos en la Nación, la provincia de Buenos Aires y la Ciudad de Buenos Aires (2007-2019). (Tesis de doctorado inédita) Doctorado en Sociología, Escuela Interdisciplinaria de Altos Estudios Sociales, Universidad Nacional de San Martín.

Schneider, B. R. (1998). "The Material Bass of Technocracy: Investor Confidence and Neoliberalism in Latin America”. En Centeno, M. y Silva, P. (eds.): The politics of expertise: technocratic ascendancy in Latin America (pp. 77-95). New York: St. Martin's Press.

Serrafero, M. (2005). Exceptocracia, ¿confin de la democracia? Intervención federal, estado de sitio y decretos de necesidad $y$ urgencia. Buenos Aires: Lumière.

Simmel, G. (2010 [1908]). Sociologie. Etudes sur les formes de la socialisation. Paris : PUF.

SINAPA. (2007). Informe de situación al 31 de diciembre del 2005. Buenos Aires: Oficina Nacional del Empleo Público.

Soprano, G. (2007). Del Estado en singular al estado en plural. Contribución para una historia social de las agencias estatales en la Argentina. Cuestiones de Sociología, 4, 19-48.

Tenti Fanfani, E. (1989). Estado y pobreza: estrategias típicas de intervención. Buenos Aires: CEAL.

Torre, J. C. (2013). Intervención de Juan Carlos Torre. Ciencias sociales y política en Argentina (pp.45-50). Santa Fe: Ed. UNL.

Vommaro, G. (2012). Los pobres y la pobreza como dominio experto: contribuciones a una socio-historia. En Morresi, S. y Vommaro, G. (comps). Saber lo que se hace. Expertos y politica en la Argentina reciente (pp. 79-134). Buenos Aires: Prometeo.

\section{Notas}

* CV resumidos de las coordinadoras: Mariana Gené es doctora en Ciencias Sociales por la UBA y en Sociología Política por la EHESS (Paris). Es investigadora asistente del CONICET y docente de grado y posgrado en el IDAES-UNSAM. También es profesora en la maestría en Teoría Social de la UBA. Sus temas de investigación abarcan la profesión política, las agencias estatales y los partidos en la Argentina reciente. Publicó artículos en revistas académicas de Argentina y del exterior, y el libro La rosca política (Siglo XXI, 2019). Mariana Heredia es doctora en Sociología en la École des Hautes Études de París. Es investigadora independiente del CONICET y docente de grado y posgrado del IDAESUNSAM, de la UBA y de la UDESA. Sus intereses de investigación abarcan la sociología económica y de las elites, desde las elites corporativas y tecnocráticas hasta las clases medias altas y altas. Publicó numerosos artículos en revistas académicas de Argentina y del exterior y dos libros: A quoi sert un économiste (La découverte, 2014) y Cuando los 
economistas alcanzaron el poder (Siglo XXI, 2015). Luisina Perelmiter es doctora en Ciencias Sociales por la UBA. Es investigadora asistente del CONICET y docente de grado y posgrado en el IDAES-UNSAM y en UDESA. Sus temas de investigación abarcan la sociología del Estado y las burocracias, las políticas sociales y regímenes de bienestar y las burocracias de calle. Publicó artículos en revistas académicas de Argentina y del exterior, y el libro Burocracia Plebeya. La trastienda de la asistencia social en el Estado argentino (UNSAM Edita, 2016).

1 Nociones como "delegacionismo" o "neodecisionismo" en el ejercicio del poder ilustran estas interpretaciones sobre los cambios del poder político en el último cuarto del siglo XX (Bosoer y Leiras, 1999; Novaro, 2001; Quiroga, 2007). En esta línea, se incluyen los trabajos que muestran la proliferación de decretos de necesidad y urgencia a partir del primer gobierno de Menem (1989-1995) (Ferreira Rubio y Goretti, 1996, 2000) y, más generalmente, el uso permanente de recursos de excepción reservados para las situaciones de crisis (Quiroga, 2005; Novaro, Bonvecchi y Cherny, 2014).

2 Los estudios de caso requirieron la reconstrucción sociohistórica de las líneas de acción, elencos de funcionarios, principales interlocutores, desafíos de gobierno y formas de visibilidad pública de cada cartera. Para ello, se utilizaron datos agregados sobre trayectorias y perfiles de funcionarios producidos en el marco de los proyectos PIP-CONICET sobre elites argentinas dirigidos por Castellani en el IDAES-UNSAM, y datos construidos a través de entrevistas en profundidad, análisis de documentos, observación participante y material de prensa.

3 Pueden mencionarse: Dalbosco, 2003; Canelo, 2012; Heredia, 2012; Perelmiter, 2012a y 2012b; Gené, 2012, 2019, Perelmiter y Paura, 2019; Salerno, 2020; Giorgi, 2020. Por su parte, el estudio pionero de De Imaz (1964) dedicó una parte especial a los ministros nacionales.

4 Se destacan, entre otros: Camerlo, 1990; Escobar-Lemmon y Taylor-Robinson, 2009; Amorim Neto, 2006; Martínez Gallardo, 2011 y 2012; Camerlo y Pérez Liñán, 2012; Camerlo y Coutinho, 2019.

5 Entre muchos otros: Markoffy Montecinos (1994), Centeno y Silva (1998), Dezalay y Garth (2002). Sobre la Argentina: Camou (1998), Beltrán (2005), Heredia (2012, 2015).

6 Para un detalle de las intervenciones federales a las provincias y su sustento jurídico desde la consolidación del Estado argentino hasta la actualidad, véase el primer capítulo de Serrafero (2005).

7 Solo dos de los ministros desde la vuelta de la democracia, por distintas razones, no detentaban casi cargos públicos en su carrera antes de llegar a la cúspide del ministerio: Enrique Nosiglia (ministro del Interior entre septiembre de 1987 y mayo de 1989) y Gustavo Béliz (ministro del Interior entre diciembre de 1992 y agosto de 1993). Ambos casos son excepcionales en su relativa ausencia de cargos formales antes de ser ministros, pero también lo son en el paroxismo de su proximidad al presidente: confidentes y consejeros fundamentales, iniciaron su carrera política al calor del ascenso de Raúl Alfonsín y Carlos Menem, con quienes mantenían relaciones singularmente estrechas (Gené, 2019).

8 Nos referimos a los Centros de Referencia, a los Centros de Integración Comunitaria, al Programa Promotores Territoriales para el Cambio Social, al Tren de Desarrollo Social y Sanitario "Ramón Carrillo", al Programa Ahí, en el lugar, entre otros.

9 Nos referimos a la construcción mítica de cierto modo de actuar frente a la pobreza y los pobres, ligado a la figura de Eva Perón, que consistía en la puesta en escena de la sensibilidad frente al sufrimiento de los humildes, el cultivo de la cercanía y el contacto cuerpo a cuerpo y la voluntad férrea de responder a ese sufrimiento caso a caso. Al respecto ver Barry et al. (2008). 